\title{
A study on bloodsucking Tabanidae and Stomoxys calcitrans (Diptera) attacking horses and cows in Northern Scania, Sweden
}

\author{
Gabriela Vaduva \\ Department of Biology, Lund University, Lund 22362, Sweden \\ E-mail: vaduva_gabriela@yahoo.se
}

$\begin{array}{ll}\text { Received: November 24, } 2015 & \text { Accepted: December 9, } 2015 \\ \text { doi:10.5296/jbls.v7i1.8611 } & \text { URL: http://dx.doi.org/10.5296/jbls.v7i1.8611 }\end{array}$

\begin{abstract}
In Sweden, during summer, grazing horses and cows are frequently exposed to bloodsucking flies. This study has been performed in the geographical areas of Gundrastorp (pasture) and Kämlehöjalt (wood pasture), in northern Scania, Sweden where the occurrences of biting flies may represent a scourge for domesticated animals. The distribution of biting flies, Tabanidae and Stomoxys calcitrans (L) (known as stable flies) was studied by insect trapping using two Nzi traps, one for each habitat. No attractants have been used in order to improve trap capture rate. This research pointed out that tabanid and stable flies did not show any preference between the two landscape types or between hosts where they get their blood meal. Capture rates increased on days with high temperature. There were also differences in number between all types of weather for both tabanid and stable flies. In terms of species activity in all types of weather, 13 species of Tabanidae displayed some differences between them in each habitat. In the genus Tabanus, Tabanus bromius and Tabanus maculicornis showed similar patterns with regards to daily activity in different types of weather, being followed by Haematopota pluvialis and Hybomitra bimaculata. Moreover, with regards to the number of male and female tabanids collected in Nzi traps, a higher difference for each area was found. As a parallel survey, the landing behavior of each genus of collected tabanids on blue and black colors before going into Nzi traps showed the same variation during the experiments. Nzi traps set near the horses and cows have shown high efficiency in capturing biting flies, allowing animals to graze somewhat undisturbed.
\end{abstract}

Keywords: Tabanidae, Stomoxys calcitrans, Species recognition, Attractiveness, Nzi trap, Temperature 


\section{Introduction}

Biting flies, tabanids and Stomoxys calcitrans (L) (Diptera), as hematophagous species are commonly livestock pests and may cause great anguish even just flying around wild and domesticated animals and also humans.

Flies of the family Tabanidae, usually known as horse flies and deer flies, are being seen around horses and cows taking a blood meal in order to maintain their annual populations (Baldacchino, et al., 2014 a). Because of their bloodsucking habits tabanids are considered a threat because they act as mechanical vectors of diseases in association with pathogens, causing bovine-leukosis, equine infectious anemia, tularemia etc., and also Anaplasma marginale, Trypanosoma vivax, Trypanosoma evansi causing surra, (Ngeranwa and Kilalo, 1994; Barros and Foil, 2007; Muzari, et al., 2010; Bawm, et al., 2015).

Some Tabanidae species such as Tabanus bromius and Haematopota pluvialis are considered vectors of T. theileri infection in cattle, in Europe and also Sweden (Dirie, et al., 1990; Neumüller, et al., 2012).

Likewise, Stomoxys calcitrans (L) is recognized as a vector of Habronema microstoma, a nematode of horses (Ndegwa and Ogodo, 2002). Furthermore, tabanids and Stomoxys calcitrans (L) are the most serious pests for the mechanical transmission of besnoitiosis. Besnoitia besnoiti (Henry, 1913) is the agent that causes the besnoitiosis disease in cattle and is widespread in Europe, Asia and Africa (Liénard, et al., 2013). Moreover, bloodsucking flies may have a great impact on milk reduction, meat yields, cattle growth, feeding efficiency and through their bites cause considerable stress to horses and cows (Birkemoe and Sverdrup-Thygeson, 2011; Bawm, et al., 2015). They also become a major constraint to livestock production. In terms of people who spend time outdoors biting flies may be extremely annoying. In a study carried out by Krčmar and Marić (2006) in Croatia, 22 species of horse flies landed preferentially on different regions of the human body. These hematophagous species depend on blood from a variety of animals in terms of their reproduction. Both sexes of Stomoxys calcitrans (L), need plenty of blood meals before being able to reproduce, as well as to satisfy the energy demands, and requirements for eggs development (Venkatesh and Morrison, 1982). As regards the tabanid females, there is a threshold in the development of eggs and in some species (i.e. Tabanus bromius) the amount of blood ingested may be similar to or exceed the female weight (Ballard and Waage, 1988). Male and female tabanids also require nectar and some species are entirely nectar feeders (Kniepert, 1980).

In monitoring the number and species of bloodsucking flies, a variety of traps were tested but none apart from the Nzi trap has been designed so efficiently and practically as to simultaneously catch a wide variety of biting flies such as tsetse, tabanid and stable flies. All studies in Africa, Australia and North America came to the same significant result (Mihok, 2002; Van Hennekeler, et al., 2008). There has been no previous research on patterns of tabanid and stable fly activity in northern Scania, Sweden. The collection of data regarding biting flies as vectors of several diseases strikes me as being necessary to identify the periods when pathogen transmission risk could be higher. 


\section{Macrothink}

Journal of Biology and Life Science

ISSN 2157-6076

2016, Vol. 7, No. 1

Based on all observations, 13 species of Tabanidae and also Stomoxys calcitrans (L) might be considered important pests of horses and cows in the pasture associated with wood pastures in northern Scania, Sweden.

One purpose of this study is to test the efficiency of unbaited Nzi traps in capturing tabanid and stable flies for the first time in Scandinavia. The present work reports an estimation of the present state of bloodsucking dipterans and their attractiveness to horses and cows in northern Scania, Sweden. The relationship between genders in tabanids is displayed in both research areas. The positive relationship between tabanids and Stomoxys calcitrans (L) activity patterns and all types of weather is pointed out. Likewise, the relationship between tabanids and stable fly daily catches and weather, (including temperature) is tested. Moreover, behavioral observations, in terms of tabanids landing on blue and dark Nzi traps color, has also been highlighted by this study.

\section{Materials and Methods}

\subsection{Traps}

Two Nzi traps have been bought from Rincon - Vitova Insectaries company (USA) in order to monitor daily catches of tabanid and stable flies (Figure 1).

They are simple, flexible cloth traps from marine grade canvas with a combination of blue, black and white colors working by attracting the flies to large black and blue objects. Each trap is 6 feet wide, 4.5 feet tall and 2 feet deep. Their shape mimics large animals and is perceived by the visual system of the fly and the front blue panel could be expected by biting flies to be the animal's "underbelly". All flies go up through the funnel directly into the collector bottle and then into the collector bag where they die because they cannot find their way back out. This type of trap could capture simultaneously a higher number of biting flies (tsetse, tabanid and stable flies) compared to other type of traps either with or without attractants (Mihok, 2002; Van Hennekeler, et al., 2008).

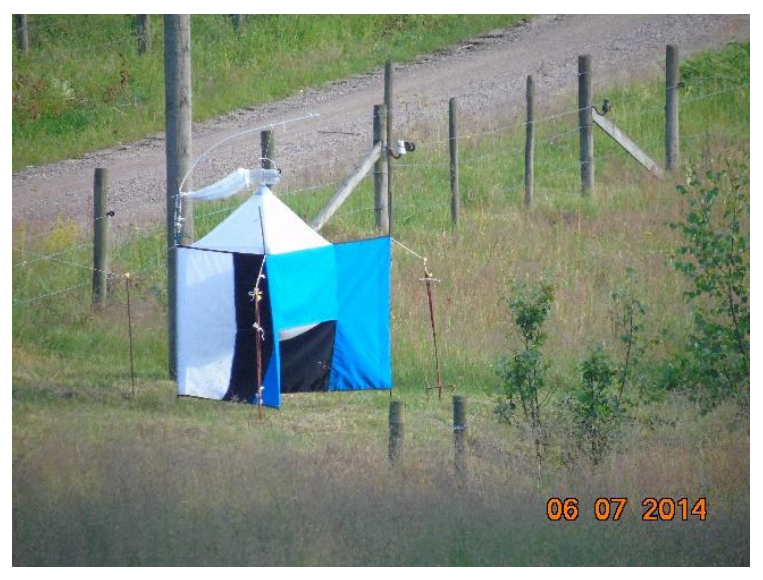

Figure 1. Nzi trap set up in Kämlehöjalt (wood pasture), Sweden, 2014

\subsection{Study Areas}

The research was carried out at two locations (Gundrastorp $56^{\circ} 21^{\prime} \mathrm{N}, 13^{\circ} 41^{\prime} \mathrm{E}$ ) and 
(Kämlehöjalt $56^{\circ} 21^{\prime} \mathrm{N}, 13^{\circ} 32^{\prime} \mathrm{E}$ ) in northern Scania, Sweden, from 25 June through 24 July 2014. Observations have been done in a pasture surrounded by meadow land and forest (Gundrastorp), and in a wood pasture (Kämlehöjalt) crossed from south to north by a forest road. In both areas there are deciduous-coniferous mixed forests where oak, beech, birch, spruce and pine can be included in different proportions. In both locations there is permanent water nearby such as a lake at approximately $500 \mathrm{~m}$ south of pasture and a small stream that crosses the wood pasture. There are also some ponds in Kämlehöjalt. The distance between the two research areas was $14 \mathrm{~km}$.

One unbaited Nzi trap was set up for each location in an open area away from trees, in order to avoid some species - specific differences. They were also fixed close to the ground, facing west as the activity of biting flies was focused on the sunny side of the trap during the afternoon (orientation) (Mihok, et al., 2006).

The sites did not change over the period of experiment due to grass growth because the grass was cleared around and under the traps when necessary.

In Gundrastorp two Norwegian horses fed on the pasture for the entire month in close proximity to the trap (that was protected by an electric wire fence).

On the wood pasture in Kämlehöjalt, 13 cows grazed at a distance of between 10 and $200 \mathrm{~m}$ from the Nzi trap (that was protected by a barbed wire fence across the forest road).

\subsection{Collection and Specimens Processing}

Tabanids and Stomoxys species were collected daily from 6 to $8 \mathrm{pm}$ in both locations.

All specimens were placed in labeled plastic vials, and then placed in a freezer overnight at $-18^{\circ} \mathrm{C}$ in order to be counted and identified the next day.

Horse flies and deer flies and also Stomoxys calcitrans (L) were identified at species level in terms of the location, catching date, gender (tabanids) and number of captured specimens. Species identification was carried out according to species descriptions and keys from Chvála, et al., (1972); Walker (1994) and Krčmar, et al., (2011).

Weather variable (temperature) was measured every day using an environment anemometer LUTRON LM-8000 before starting the collection of specimens.

\subsection{Behavioral Observations of Tabanids Landing On Nzi Traps}

These field observations lasted two hours per day in each location and only on the sixteen sunny days in both Gundrastorp (between 11.00 and 13.00) and Kämlehöjalt (from 13.30 to 15.30). As observer I stood at a distance of 50 centimeters from each trap and I recorded all tabanids by genus (in order to be identified directly) landing on the blue and black color surfaces of Nzi traps. The duration of landing was approximately measured each time for each genus. After a while each specimen entered inside the Nzi trap and was caught there without any chance to escape. 


\subsection{Data Analysis}

In order to comply with a normal distribution, the number of tabanids and stable flies was transformed to $\log 10(n+1)$ before the computation of variance analyses.

All statistical analyses were performed using SPSS 22.0.

\section{Results}

During this study a total number of 4332 specimens in the family Tabanidae and of the species, S. calcitrans (L) were captured in both locations. With respect to tabanid flies, 13 species have been captured in each location and constituted $68.67 \%(\mathrm{n}=2975)$ of the total specimens captured (table 1). Stable flies (S. calcitrans) represented 31.33\% ( $\mathrm{n}=1357)$. Tabanus bromius constituted over $30 \%(\mathrm{n}=1016)$ of the total number of specimens collected and it was the most abundant species present in each location. It was followed by Tabanus maculicornis 29.98\% ( $\mathrm{n}=892)$, Hybomitra bimaculata $7.23 \%(\mathrm{n}=215)$ and Haematopota pluvialis $6.55 \%(\mathrm{n}=195)($ Table 1$)$.

Table 1. Tabanid species (number and percentage) collected in both research locations.

\begin{tabular}{|l|r|r|r|c|r|r|}
\hline \multirow{2}{*}{ Species } & \multicolumn{2}{|c|}{ Gundrastorp } & \multicolumn{2}{c|}{ Kämlehöjalt } & \multicolumn{2}{c|}{ Total (2 locations) } \\
\cline { 2 - 8 } & \multicolumn{1}{c|}{$\mathrm{n}$} & \multicolumn{1}{c|}{$\%$} & \multicolumn{1}{c|}{$\mathrm{n}$} & \multicolumn{1}{c|}{$\%$} & \multicolumn{1}{c|}{$\mathrm{n}$} & \multicolumn{2}{c|}{$\%$} \\
\hline Tabanus bromius L., 1758 & 475 & $32.76 \%$ & 541 & $35.48 \%$ & 1016 & $34.15 \%$ \\
\hline Tabanus maculicornis Zetterstedt, 1842 & 402 & $27.72 \%$ & 490 & $32.13 \%$ & 892 & $29.98 \%$ \\
\hline Tabanus bovinus L., 1758 & 10 & $0.69 \%$ & 14 & $0.92 \%$ & 24 & $0.81 \%$ \\
\hline Tabanus sudeticus Zeller, 1842 & 2 & $0.14 \%$ & 5 & $0.33 \%$ & 7 & $0.24 \%$ \\
\hline Hybomitra solstitialis (Meigen, 1820) & 43 & $2.97 \%$ & 71 & $4.66 \%$ & 114 & $3.83 \%$ \\
\hline Hybomitra bimaculata (Macquart, 1826) & 127 & $8.76 \%$ & 88 & $5.77 \%$ & 215 & $7.23 \%$ \\
\hline Hybomitra lundbecki Lyneborg, 1959 & 69 & $4.76 \%$ & 19 & $1.25 \%$ & 88 & $2.96 \%$ \\
\hline Hybomitra kaurii Chvála et Lyneborg, 1970 & 60 & $4.14 \%$ & 62 & $4.07 \%$ & 122 & $4.10 \%$ \\
\hline Hybomitra lurida (Fallén, 1817) & 37 & $2.55 \%$ & 22 & $1.44 \%$ & 59 & $1.98 \%$ \\
\hline Hybomitra montana (Meigen, 1820) & 30 & $2.07 \%$ & 30 & $1.97 \%$ & 60 & $2.02 \%$ \\
\hline Hybomitra muehlfeldi (Brauer, 1880) & 74 & $5.10 \%$ & 39 & $2.56 \%$ & 113 & $3.80 \%$ \\
\hline Haematopota pluvialis L., 1758 & 89 & $6.14 \%$ & 106 & $6.95 \%$ & 195 & $6.55 \%$ \\
\hline Chrysops viduatus (Fabricius, 1794) & 32 & $2.21 \%$ & 38 & $2.49 \%$ & 70 & $2.35 \%$ \\
\hline TOTAL & 1450 & $100 \%$ & 1525 & $100 \%$ & 2975 & $100 \%$ \\
\hline
\end{tabular}

Notes: $\mathrm{n}$, number of specimens in every species; $\%$, percentage of each species of the total number of collected tabanids individuals. Collection period using unbaited Nzi traps was recorded from June 25 to July 24, 2014.

Based on the total number of tabanids and stable flies there was a significant difference between Tabanidae and Stomoxys calcitrans (L) at Gundrastorp ( $t$-test: $t=2.99, d f=58, P=$ 0.004; Figure 2a) and respectively, Kämlehöjalt ( $t$-test: $t=3.4, d f=58, P<0.001$; Figure $2 \mathrm{~b}$ ). 
(a)

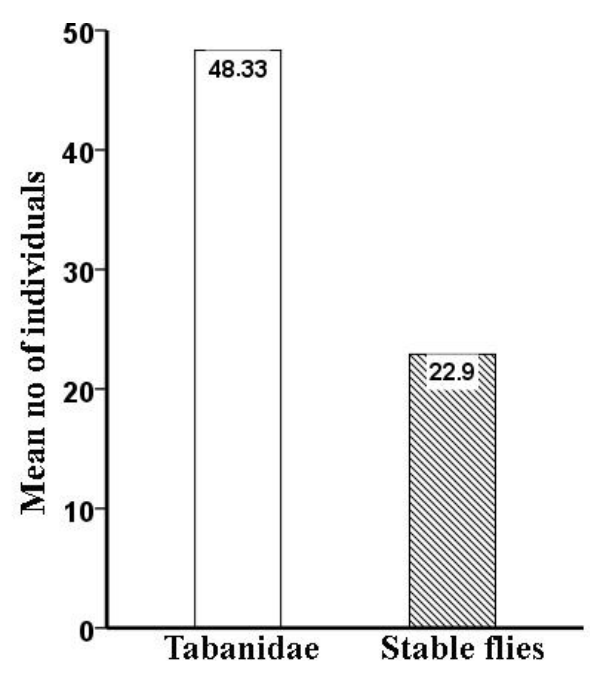

(b)

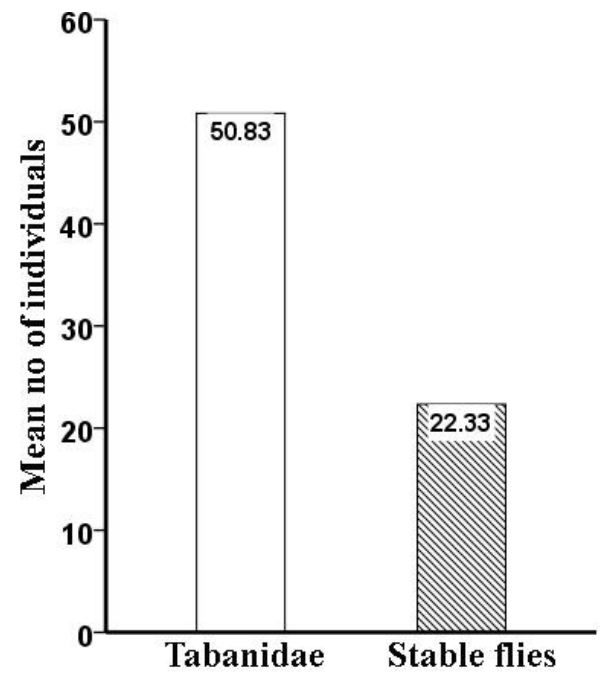

Figure 2. Number of individuals captured in both locations. The mean number of individuals and their taxonomic rank (family Tabanidae and S. calcitrans (L) species) in a Gundrastorp or

b Kämlehöjalt and captured within 30 days (tabanids: (a) $n=1450$; (b) $n=1525$ and stable

$$
\text { flies: (a) } n=687 \text {; (b) } n=670 \text { ). }
$$

The number of male and female tabanids from both locations was highly significantly different. The gender had influence on the average number of captured individuals (analysis of variance, ANOVA: $F(1,116)=83.27, P<0.001$; Figure 3$)$.

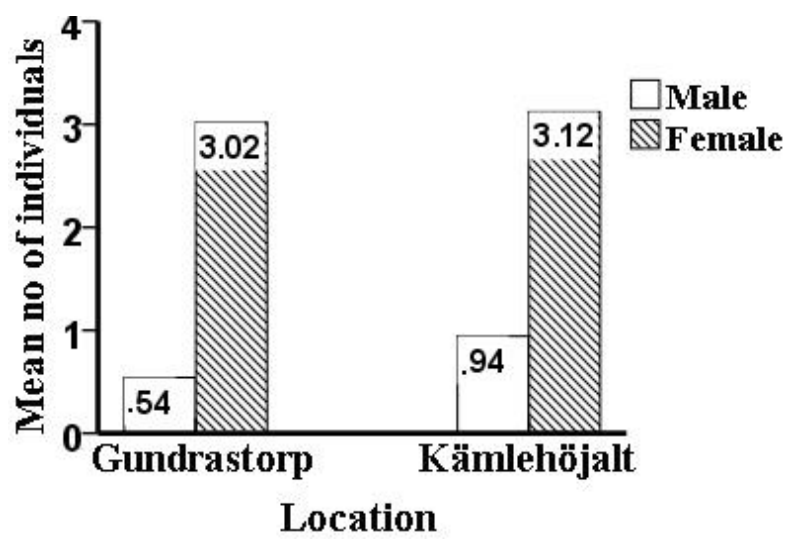

Figure 3. Distribution of Tabanidae depending on sex and location. The distribution of average number of individuals between males and females in each location. As regards the capture rate, males $(n=57)$; females $(n=1393)$ in Gundrastorp and Kämlehöjalt respectively, males $(n=113)$ and females $(n=1412)$.

When testing whether the number of captured tabanid flies in both locations depended on the type of weather, ANOVA revealed a significant difference $F(1,52)=295.11, P<0.001$. Tukey HSD $(P<0.001)$ showed a significant difference in the total number of tabanids between all types of weather (Figure 4a). The same pattern was evident for stable flies in Gundrastorp and Kämlehöjalt in terms of weather (ANOVA: $F(1,52)=51.69, P<0.001$ ). Moreover, Tukey HSD $(P<0.001)$ showed again a significant difference in the total number 


\section{Macrothink}

of stable flies between all types of weather, except a non - significant difference $(P=0.36)$ in the number of Stomoxys calcitrans (L) between partly cloudy and cloudy days (Figure 4b).

(a)

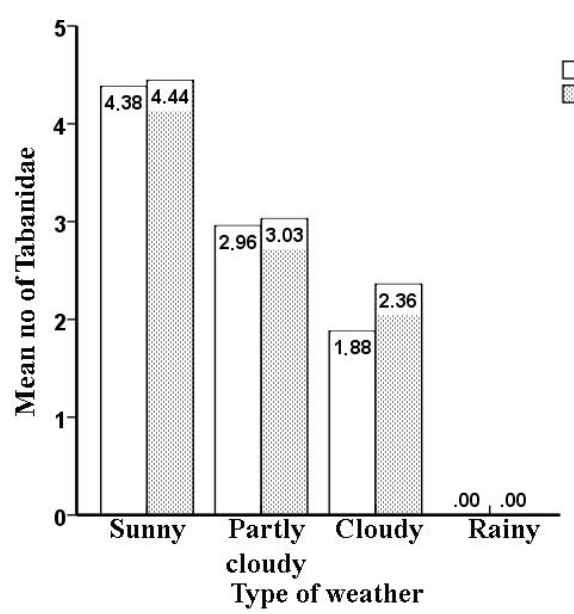

(b)

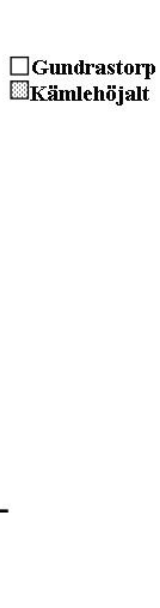

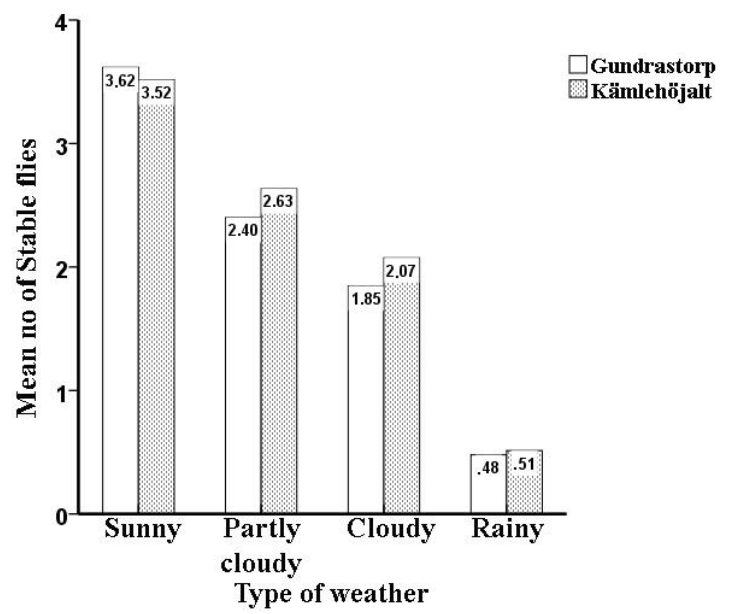

Figure 4. Captured tabanid and stable flies according to all types of weather $\&$ location.

(a) The mean number of Tabanidae and (b) S. calcitrans (L) that were captured during the entire period in Gundrastorp and Kämlehöjalt. The numbers displayed above the columns are mean numbers of captured individuals during each type of weather in each of the two locations.

When restricting the analyses to the activity of all tabanid species with regards to weather it turned out that there was a significant difference in numbers of individuals between species in each location (ANOVA: $F(13,208)=25.69, P<0.001$ ) and also between all types of weather $($ ANOVA: $F(13,208)=73.55, P<0.001$; Figure 5$)$.

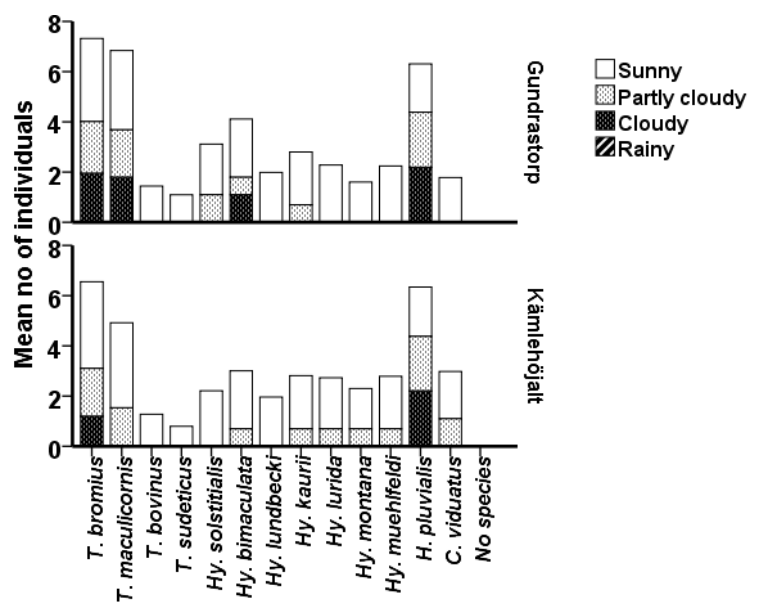

Figure 5. Species of tabanids caught in each location on different types of weather. 13 tabanid species were captured in Gundrastorp and also in, Kämlehöjalt with the exception of no species in rainy weather. $\mathrm{T}=$ Tabanus $; \mathrm{Hy}=$ Hybomitra $; \mathrm{H}=$ Haematopota $; \mathrm{C}=$ Chrysops . 


\section{$\triangle$ Macrothink}

When comparing the capture rate of tabanid and stable flies between days, the result displayed out a significant difference between date (ANOVA: $F(29,60)=130.54, P<0.001$ ) and the same pattern between tabanids and Stomoxys calcitrans (L) (ANOVA: $F(29,60)=$ 95.07, $P<0.001$ ). Between the two locations there was no significant difference (ANOVA: $F$ $(29,60)=0.31, P=0.58$; Figure 6$)$.

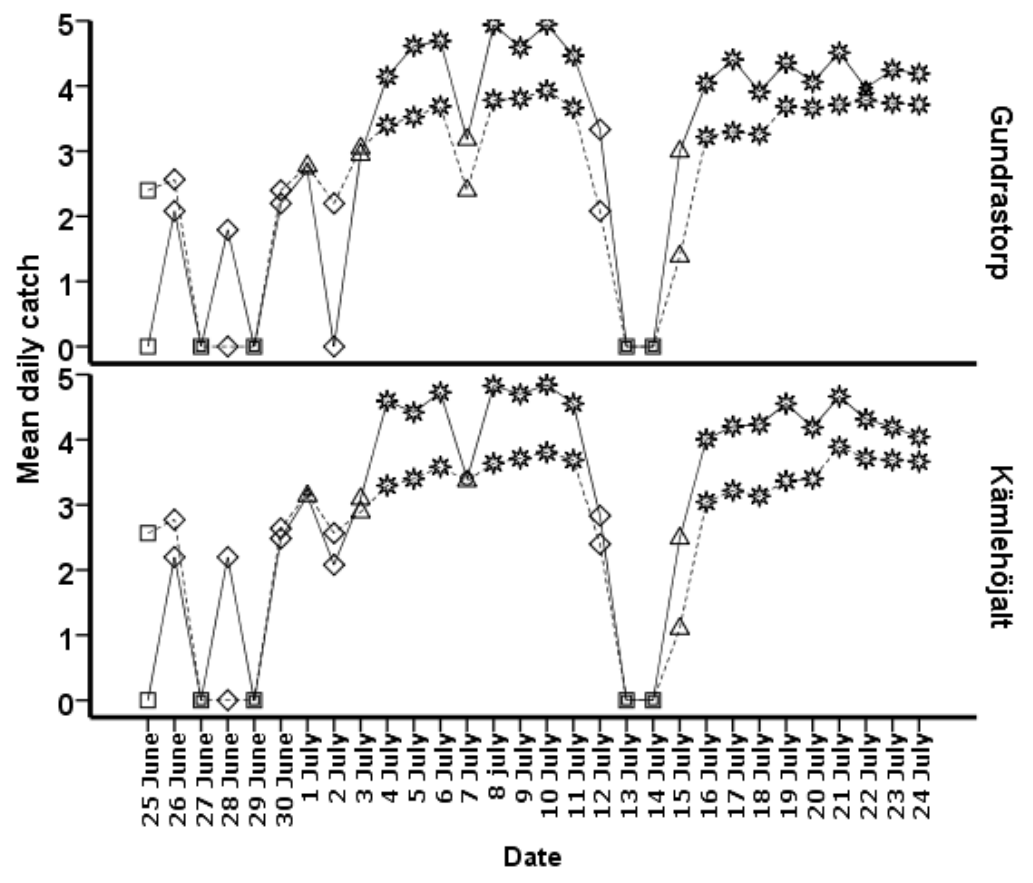

Figure 6. Relationship between daily catches of Tabanidae and S. calcitrans (L) in each research area. Mean daily catches are related to the types of weather and the temperature. Data for sunny days are shown by open stars, for partly cloudy by open triangles, for cloudy by open diamonds and for rainy by open squares. Tabanids are represented by a solid line and Stomoxys calcitrans (L) through a dotted line.

\section{Discussion}

Before this study nothing was known about Nzi trap efficiency in capturing tabanid and stable flies in Scandinavia. The result of this research strongly supports the hypothesis that Nzi traps are able to catch a high number of different bloodsucking flies here in Sweden as previously shown in Africa, North America and Australia (Mihok, 2002; Mihok, et al., 2006; Van Hennekeler, et al., 2008; Baldacchino, et al., 2014 b). These types of traps are more efficient than more specialized traps in catching tabanids, tsetse and stable flies (Mihok, 2002). Nzi traps with non-shiny surfaces as a condition in capturing rate of biting flies has been highly efficient. The traps in both locations have been set in open areas not close to the edge of forest and oriented facing west in order to increase their efficiency in catching Tabanidae and Stomoxys calcitrans (L) (Mihok, et al., 2006; Baldacchino, et al., 2014 b).

Capture rates of Stomoxys calcitrans (L) are not influenced by Nzi traps baited with a variety of different attractants (i.e. octenol) (Mihok, et al., 2007). As regards tabanids number captured with unbaited Nzi traps it could remain higher without any attractants comparing for 
instance with canopy traps. Moreover, monitoring over long periods, especially in remote areas, would not be possible using attractants because of the difficulty to ensure a consistent emission rate of attractants over time (Van Hennekeler, et al., 2008). However, the use of dry ice could be costly for livestock breeders and also difficult. Likewise, in some geographic areas the number of captured tabanid flies could be reduced by using baited traps with aged urine from domestic animals (Krčmar, et al., 2006). Thus, in this study I tested whether unbaited Nzi traps are particularly attractive to bloodsucking flies.

Capture percentages among species of tabanids had high variation in each location. Tabanus bromius and Tabanus maculicornis species have been the most abundant in both research areas. These species are commonly widespread throughout Europe (Krčmar and Leclercq, 1999). They have been followed in their activity pattern by Hybomitra bimaculata (common species present near lakes as in Gundrastorp and ponds in Kämlehöjalt) and Haematopota pluvialis, both with a wide European distribution. Furthermore, Tabanus sudeticus and Tabanus bovinus were represented by a small number of individuals. This was an unexpected result since these species of Tabanidae are known to be spread in Sweden (Chvála, et al., 1972). One hypothesis could be that these species are usually limited to certain areas in Sweden, according to altitude and/or vegetation. These factors might determine species richness, tabanids abundance and distribution. A second hypothesis may agree with some previous studies in terms of seasonal succession with respect to the main species. This may be a strategy leading to a small interspecific competition between species of Tabanidae. A third hypothesis might be linked to seasonal dynamics, with weather variability playing a major role in tabanid species emergence and their peak of activity (Baldacchino, et al., 2014 b). All three hypotheses may more or less explain the variation in the number of individuals between species of Tabanidae. Furthermore, horse flies are more attracted to large objects than deer flies and this could explain the small number of Chrysops viduatus caught in Nzi traps (Davies, 1959).

Between locations the capture percentage for all species, except some Hybomitra spp, did not show too much variation.

The number of captured specimens was almost similar both for tabanid and stable flies between pasture and wood pasture. By comparison, it seems that the type of animal and also the habitat have played the same role in attracting the biting flies. A good explanation could be the presence of bodies of water in both areas and also the presence of forest (Chvála, et al., 1972). Wood pastures may be of a particular interest for tabanids that use them as resting places and for searching for hosts in order to take their meal. Moreover, the pasture was surrounded by meadow with a small number of shrubs and lines of forest at the edges. Tabanids are recognized to be fast fliers flying far away from the breeding sites in their host-seeking movement (Barros and Foil, 2007; Baldacchino, et al., 2014 b). The presence of animals in the two areas as well as their manure (used by ovipositing females) influenced positively the number of Stomoxys calcitrans (L). Stable flies are known as a significant pest seriously affecting horses and cattle (Jeanbourquin and Guerin, 2007). Likewise, from the total number of specimens caught in the two traps, tabanids dominated in each location whereas the catches of stable flies were smaller across the experiments. This appears to be 
related to stable fly feeding activity that begins many hours after sunrise and peaking around noon (Birkemoe and Sverdrup-Thygeson, 2011). As regards the tabanids' feeding habits, females attack livestock and sometimes humans and this takes place between sunrise and sunset. They begin to feed before 7 a.m. and some species (Chrysops and Haematopota spp.) have seen feeding just before 9 p.m. (Chvála, et al., 1972). Another assumption includes the age of the host that might play a crucial role in the stable fly' biting rates especially as regards the cattle (Torr, et al., 2006). The difference in the number of male and female tabanids in Gundrastorp and Kämlehöjalt was highly significant. The number of female individuals in each location has been around 24 times greater than in males. These types of traps not only captured females during their host seeking but also a number of males. This was manifested in the performance of Nzi traps imitating the shape of animals in capturing tabanid females. The presence of males in the traps suggests that they are using them as "waiting stations" presumably for chasing females in the warm afternoons (Mihok, et al., 2006).

The activity pattern of specimens was most common in sunny weather (Figs. 3a, 3b). Based on the number of tabanids and Stomoxys calcitrans (L) there was an activity peak in sunny weather with a marked decrease in partly cloudy or cloudy weather. Catch levels of Tabanidae are known to be affected by cloud cover but not by warm conditions (Van Hennekeler, et al., 2011). Moreover, the effect of weather on the number of stable flies was striking but in contrast, catches of Stomoxys calcitrans (L) were similar in both partly cloudy and cloudy weather. However, there was an overall activity of stable flies in rainy weather compared with the absence of tabanids in Nzi traps on this type of weather.

The number of specimens for each species of tabanids attracted to horses and cattle varied markedly between species and also in every type of weather.

The most active species in all types of weather were Tabanus bromius and Haematopota pluvialis (which feed in cloudy weather; Chvála, et al., 1972) both in pasture and wood pasture. Tabanus maculicornis and Hybomitra bimaculata have been more active in all types of weather in Gundrastorp whereas in Kämlehöjalt only on sunny and partly cloudy days. All other species were active in higher proportion in sunny and partly cloudy weather. However, Tabanus bovinus, Tabanus sudeticus and Hybomitra lundbecki had activity only on sunny days in both locations. During rainy days, tabanids had no activity at all. Different species of Tabanidae could respond differently to weather variables (especially temperature) with varied activity pattern (Van Hennekeler, et al., 2011). Large species like those from the genus Tabanus or medium size species (genus Hybomitra) have been more active when the wind did not blow or the speed was low. In contrast, small species (i.e. Chrysops viduatus and Haematopota pluvialis) increased their activity in high temperatures (Baldacchino, et al., 2014 a).

Furthermore, temperature is presumably a more decisive weather variable for tabanids than intensity of light. When the temperature is lower tabanid flies are less active, which could explain their small number captured in certain days (Chvála, et al., 1972). Tabanid and stable flies displayed such difference between them in daily capture rates in each research area. Despite these differences, tabanid species and Stomoxys calcitrans (L) were particularly 
strongly influenced by the type of weather and temperature. Moreover, throughout the day each tabanid species may responds differently to weather variables (Van Hennekeler, et al., 2011).

For instance, in their response to weather, on sunny windless days with an average temperature of $22.9^{\circ} \mathrm{C}$, the bloodsucking flies had a particularly high activity. On partly cloudy (average $18.5^{\circ} \mathrm{C}$ ) and cloudy days (average $17^{\circ} \mathrm{C}$ ) the biting flies were captured in differently high proportions. Likewise, at high temperatures stable flies become warmed up looking for food and for places to lay their eggs (Bawm, et al., 2015). Rainy days with a temperature not significantly above the threshold $\left(15^{\circ} \mathrm{C}\right)$ made the tabanids unable to fly. With respect to Stomoxys calcitrans (L) the catches on rainy days took place only on the first day. The stable fly immature stages could be extremely sensitive to humidity and rain conditions ((Bawm, et al., 2015).

Bloodsucking flies have a high level of attraction to blue and dark objects (Mihok, et al., 2006). Nzi traps include large fabric quantities of blue color to attract flies in combination with black panels of smaller size to induce landing (Mihok, 2002).

The behavior of individual species of tabanids as regards the speed and landing on different colors of Nzi traps surfaces varied significantly. Therefore, individuals of Chrysops and Haematopota genus have been observed coming in at low speed and then landing preferentially on a blue color where they spend some minutes before entering the traps. Tabanus and Hybomitra genus were coming at relatively high speed, landing on the black color followed by going inside the trap after a few seconds.

These observations point out the necessity for further investigations of tabanids in their responses to visual cues such as color, and especially contrast.

Nzi traps have been shown to be useful in capturing Tabanidae and Stomoxys calcitrans (L) offering an option in the suppression of bloodsucking flies.

Further studies will be needed to determine distributions and density of tabanid and stable flies because some habitats remain extremely poorly known in terms of their fauna. Moreover, a continuation of faunal and ecological studies in these areas would be necessary because the 13 species identified are without doubt not the only species existing in these locations. Nzi traps could be extremely efficient for faunal surveys in a wide variety of habitat types.

\section{Acknowledgments}

I acknowledge Jerry Olsson and Lena Svensson from Gundrastorp for their agreement to run the research on their properties and Denis Vaduva for invaluable aid in the field.

This study has been funded by a grant (to G. V.) from Stiftelsen Lunds Djurskyddsfond Lund, Sweden.

I am fully grateful to the readers of the manuscript Professors Eric Warrant and Thomas Pape, Mikael Sörensson, Mogens Andersen and other anonymous readers for their valuable feedback. 


\section{References}

Baldacchino F., Puech L., Manon S., Hertzog L. R., \& Jay-Robert P. (2014 a). Biting behaviour of Tabanidae on cattle in mountainous summer pastures, Pyrenees, France, and effects of weather variables. Bulletin of Entomological Research, 104, 471-479. http://dx.doi.org/10.1017/S0007485314000170

Baldacchino F., Porciani A., Bernard C., \& Jay-Robert P. (2014 b). Spatial and temporal distribution of Tabanidae in the Pyrenees Mountains: the influence of altitude and landscape structure. Bulletin of Entomological Research, 104, 1-11. http://dx.doi.org/10.1017/S0007485313000254

Ballard J. W. O., \& Waage J. K. (1988). Feeding strategies of the horseflies Hybomitra expollicata and Tabanus bromius in southern France. Medical and Veterinary Entomology, 2, 265-270. http://dx.doi.org/10.1111/j.1365-2915.1988.tb00194.x

Barros A. T. M., \& Foil L. D. (2007). The influence of distance on movement of tabanids (Diptera: Tabanidae) between horses. Veterinary Parasitology, 144, 380-384. http://dx.doi.org/10.1016/j.vetpar.2006.09.041

Bawm S., Soe T. T., \& Htun L. L. (2015). Seasonal abundance of horse flies (Diptera: Tabanidae) and stable fly (Diptera: Muscidae) collected by Nzi trap within Taw Area, Myanmar. Journal of Environmental and Applied Research, 3, 1-6.

Birkemoe T., \& Sverdrup-Thygeson A. (2011). Stable fly (Stomoxys calcitrans) and house fly (Musca domestica) densities: a comparison of three monitoring methods on pig farms. Journal of Pest Science, 84, 273-280. http://dx.doi.org/10.1007/s10340-011-0352-7

Chvála M., Lyneborg L., \& Moucha J. (1972). The horse flies of Europe (Diptera, Tabanidae). Copenhagen: Entomological Society of Copenhagen

Davies D. M. (1959). Seasonal Variation of Tabanids (Diptera) in Algonquin Park, Ontario. The Canadian Entomologist, 91, 548-553. http://dx.doi.org/10.4039/Ent91548-9

Dirie M. F., Bornstein S., Wallbanks K. R., Stiles J. K., \& Molyneux D. H. (1990). Zymogram and life-history studies on trypanosomes of the subgenus Megatrypanum. Parasitology Research, 76, 669-674.

Jeanbourquin P., \& Guerin P. M. (2007). Sensory and behavioural responses of the stable fly Stomoxys calcitrans to rumen volatiles. Medical and Veterinary Entomology, 21, 217-224. http://dx.doi.org/10.1111/j.1365-2915.2007.00686.x

Kniepert F. W. (1980). Blood-Feeding and Nectar-Feeding in Adult Tabanidae (Diptera)*. Oecologia, 46, 125-129. http://dx.doi.org/10.1007/BF00346976

Krčmar S., \& Leclercq M. (1999). Horse Flies (Tabanidae) a Contribution to the Knowledge about the Biodiversity of Lonjsko Polje. Bulletin Société royale belge d'Entomologie Koninklijke Belgische Vereniging voor Entomologie, 135, 209-213.

Krčmar S., \& Marić S. (2006). Analysis of the Feeding Sites for some Horse Flies (Diptera, 
Tabanidae) on a Human in Croatia. Collegium Antropologicum, 30, 901-904.

Krčmar S., Mikuska A., \& Merdić E. (2006). Response of Tabanidae (Diptera) to different natural attractants. Journal of Vector Ecology, 31, 262-265.

Krčmar S., Hackenberger D. K., \& Hackenberger B. K. (2011). Key to the horse flies fauna of Croatia (Diptera, Tabanidae). Periodicum Biologorum 113

Liénard E., Salem A., Jacquiet P., Grisez C., Prévot F., Blanchard B., Bouhsira E., \& Franc M. (2013). Development of a protocol testing the ability of Stomoxys calcitrans (Linnaeus, 1758) (Diptera: Muscidae) to transmit Besnoitia besnoiti (Henry, 1913) (Apicomplexa: Sarcocystidae). Parasitology Research, 112, 479-486. http://dx.doi.org/10.1007/s00436-012-3157-6

Mihok S. (2002). The development of a multipurpose trap (the Nzi) for tsetse and other biting flies. Bulletin of Entomological Research, 92, 385-403. http://dx.doi.org/10.1079/BER2002186

Mihok S., Carlson D. A., Krafsur E. S., \& Foil L. D. (2006). Performance of the Nzi and other traps for biting flies in North America. Bulletin of Entomological Research, 96, 387-397.

Mihok S., Carlson D. A., \& Ndegwa P. N. (2007). Tsetse and other biting fly responses to Nzi traps baited with octenol, phenols and acetone. Medical and Veterinary Entomology, 21, 70-84. http://dx.doi.org/10.1111/j.1365-2915.2007.00665.x

Muzari M. O., Skerratt L. F., Joner R. E., \& Duran T. L. (2010). Alighting and feeding behaviour of tabanid flies on horses, kangaroos and pigs. Veterinary Parasitology, 170, 104-111. http://dx.doi.org/10.1016/j.vetpar.2010.01.028

Ndegwa P. N., \& Ogodo J. A. (2002). Community structure and diel activity patterns of Stomoxyinae from odour-baited Nzi trap collections. Insect Science \& it's Application, 22, 275-280. http://dx.doi.org/10.1017/S1742758400020890

Neumüller M., Nilsson K., \& Påhlson C. (2012). Trypanosoma spp. In Swedish game animals. Parasitology Research, 110, 135-139. http://dx.doi.org/10.1007/s00436-011-2462-9

Ngeranwa J. J. N., \& Kilalo D. C. (1994). The ability of Stomoxys calcitrans and mechanical means to transmit Trypanosoma (Brucei) evansi from goats to camels in Kenya. Veterinary Research Communications, 18, 307-312.

Torr S. J., Mangwiro T. N. C., \& Hall D. R. (2006). The effects on host physiology on the attraction of tsetse (Diptera: Glossinidae) and Stomoxys (Diptera: Muscidae) to cattle. Bulletin of Entomological Research, 96, 71-84. http://dx.doi.org/10.1079/BER2005404

Van Hennekeler K., Jones R. E., Skerratt L. F., Fitzpatrick L. A., Reid S. A., \& Bellis G. A. (2008). A comparison of trapping methods for Tabanidae (Diptera) in North Queensland, Australia. Medical and Veterinary Entomology, 22, 26-31. http://dx.doi.org/10.1111/j.1365-2915.2007.00707.x 


\section{Macrothink}

Van Hennekeler K., Jones R. E., Skerratt L. F., Muzari M. O., \& Fitzpatrick L. A. (2011). Meteorological effects on the daily activity patterns of tabanid biting flies in northern Queensland, Australia. Medical and Veterinary Entomology, 25, 17-24. http://dx.doi.org/10.1111/j.1365-2915.2010.00900.x

Venkatesh K., \& Morrison P. E. (1982). Blood Meal as a Regulator of Triacylglycerol Synthesis in the Haematophagous Stable Fly, Stomoxys calcitrans. Journal of Comparative Physiology, 147, 49-52. http://dx.doi.org/10.1007/BF00689289

Walker A. (1994). Arthropods of humans and domestic animals. A guide to preliminary identification. London: Chapman \& Hall.

\section{Copyright Disclaimer}

Copyright for this article is retained by the author(s), with first publication rights granted to the journal.

This is an open-access article distributed under the terms and conditions of the Creative Commons Attribution license (http://creativecommons.org/licenses/by/3.0/). 